\title{
Extended Release of Timolol from Ethyl Cellulose Microparticles Laden Hydrogel Contact Lenses
}

\author{
Furqan A. Maulvi ${ }^{1, *}$, Tejal G. Soni ${ }^{2}$ and Dinesh O. Shah ${ }^{3,4,5}$
}

\author{
${ }^{I}$ Maliba Pharmacy College, Uka Tarsadia University, Surat 394350, India; ${ }^{2}$ Faculty of Pharmacy, Dharmsinh Desai \\ University, Nadiad 387001, India; ${ }^{3}$ Shah-Schulman Center for Surface Science and Nanotechnology, Dharmsinh Desai \\ University, Nadiad 387001, India; ${ }^{4}$ Department of Chemical Engineering and Department of Anesthesiology, University \\ of Florida, Gainesville, FL 32611, United States; ${ }^{5}$ School of Earth and Environmental Sciences, Columbia University, \\ New York 10027, United States of America
}

\begin{abstract}
Glaucoma is a second leading cause of blindness globally after cataract, which is managed through eye drops, which are highly inefficient due to a low bioavailability of less than 1-5\%. Frequent administration of eye drops leads to incompliance in patients, so there is a great need for medical device such as contact lenses to treat glaucoma. The objective of research was to provide sustained ocular delivery of timolol via prototype poly (hydroxyethyl methacrylate) hydrogel contact lenses which may improve bioavailability due to increase in ocular residence time of drug. The present work was to encapsulate drug in ethylcellulose microparticles, and to entrap these microparticles in the hydrogel. Microparticles were prepared by spray drying method using different ratios of drug to ethylcellulose. The solid state characterization studies of drug loaded microparticles revealed the transformation of drug to an amorphous state. The hydrogels were characterized by studying their optical and physical properties to determine their suitability as extended wear contact lenses. Microparticles laden hydrogels were compared with direct drug loaded hydrogels. The study of microparticles laden hydrogels showed reduction in optical and physical properties and the impact was proportional to the amount of microparticles in hydrogels. The results suggest the application of optimization and nanotechnology. In vitro drug release study revealed that direct loading batch delivers drug for 22 hours with high drug loading of $150 \mu \mathrm{g}$, while microparticles laden hydrogel deliver drug up to 48 hours (zero order kinetics) with low drug loading of $50 \mu \mathrm{g}$. The hydrogels appeared safe in the cytotoxicity study. The study demonstrated the promising potential of loading the ethyl cellulose microparticles into hydrogels to serve as a good platform for sustained ophthalmic drug delivery.
\end{abstract}

Keywords: Cytotoxicity, hydrogel contact lenses, spray drying, sustained drug delivery, timolol.

\section{INTRODUCTION}

More than $90 \%$ of ophthalmic drugs are delivered through eye drops. This route of administration is inefficient due to low bioavailability of less than $5 \%$, and hence requires frequent instillation to maintain the drug concentration within the therapeutic window. Also, according to John C. Lang, the drug loss in the systemic circulation causes potential side effects [1-4].

Several systems have been developed in order to improve the pre-corneal residence time and penetration through the cornea, like in-situ gels and ointments which minimize nasolachrymal drainage but can cause blurred vision [5-8, 50]. Several polymeric drug delivery systems (DDS) have being developed, however, limitation of DDS includes poor chemical stability of liposomes, physical instability in nanoparticles, fusion in niosomes, complex synthetic route for dendrimers and limited drug loading capacity, etc. [9-11]. Implants can efficiently provide sustained drug delivery, but the risk of surgery limits their use [12]. According to a study

*Address correspondence to this author at the Maliba Pharmacy College, Uka Tarsadia University, Bardoli - Mahuva Road, Tarsadi, Dist. Surat 394350, Gujarat, India; Tel: +91 8238651055; Fax: +91 02625 255882;

E-mail: furqan.maulvi@utu.ac.in performed by Himanshu Gupta in 2009 and other researchers, most of these systems sustained the drug release by only a few hours [13]. Therefore, there is a need for a new drug delivery system for sustained drug delivery.

The contact lens market globally comprises of daily disposables $(58 \%)$, soft frequent replacement lens $(8 \%)$, silicone hydrogels $(28 \%)$, soft traditional lens $(2 \%)$ and rigid lens $(5 \%)[14,15]$. According to the annual 'Trends in contact lens prescribing' survey at the University of Manchester, soft lenses are dominated by daily disposables $(45 \%)$ and monthly replaced lenses (52 \%), this survey clearly demonstrates an increase in usage of daily disposable soft contact lenses in today's global market [16]. Contact lens can be used to prolong the ocular residence time of drug for more than 30 minutes. The increase in drug residence time leads to reduce drug wastage and increase bioavailability $[17,18]$. Contact lens can be developed as an ideal medical device for ophthalmic drug delivery, as the drug residence time in the post-lens tear film (POLTF) is about 30 minutes, which is significantly higher than that of drugs delivered as eye drops, which is about 5 minutes [19-21].

Soft contact lenses were initially used for drug delivery by Sedlavek in 1965 [22, 23]. Soaking method was successfully used by Chi Chang, for ophthalmic drug delivery, but 
the major problem of loading drug by this method is that the loaded drug diffuses out in a very short time (few hours), which is inadequate for sustained drug delivery applications $[1,24]$. To improve/retard drug release durations, Chauhan et al. have proposed the development of nanoparticle laden gels that can load substantial amount of drug in the gel, which can be released at a controlled rate from the nanoparticles [25]. Hiratani et al. focused on developing imprinted contact lenses [26, 27]. Peng et al. have proposed the use of vitamin $\mathrm{E}$ for sustaining the drug delivery through contact lenses [28]. Gulsen et al. encapsulated drugs in oil-in-water $(\mathrm{o} / \mathrm{w})$ microemulsions, and dispersed microemulsions in $\mathrm{p}$ HEMA gels [29]. These systems delivered the drug for prolonged period of time, but suffered from several deficiencies including limitations on drug loading amount, short release durations, drug release during storage and impact on optical and physical properties of contact lens such as transparency, ion and oxygen permeability, etc. [30].

Therapeutic contact lenses for sustained drug delivery to treat glaucoma have being developed by many researchers. The lack of compliance associated with glaucoma therapy through eye drops could be potentially minimized by developing an extended release device, such as contact lenses. Thus, in addition to increase in bioavailability and reduced side effects, use of contact lens could improve patient adherence and thus led to better patient care and better clinical outcomes in glaucoma [2, 31-33]. This novel drug delivery method would also overcome cardiac side effects associated with timolol [34, 35]. Timolol, a non-selective betaadrenergic receptor antagonist, act by decreasing production of aqueous humor through blocking beta receptors in the ciliary body to reduce the intra ocular pressure [36].

The purpose of the study was to develop the timolol loaded ethyl cellulose microparticles laden hydrogel material that can be used as extended wear contact lens. To achieve this objective timolol loaded ethyl cellulose microparticles were prepared using spray drying technology and entrapped in hydrogel sheets. The microparticles loaded hydrogels were characterized to explore drug release kinetics, transparency, swelling, $\mathrm{Na}^{+}$ion permeabilities and wettability. Furthermore, cytotoxicity studies are conducted to establish safety of particle loaded contact lenses. If such novel therapeutic hydrogel contact lenses are placed on the eye, the drug will slowly diffuse from the matrix of ethyl cellulose, travel through the lens matrix and enter the postlens and prelens tear film, with much longer residence time in the eye in comparison to eye drops. Thus the aim of the present study was to develop sustained release ophthalmic drug delivery system using timolol loaded ethyl cellulose microparticles laden hydrogel contact lenses.

\section{MATERIALS AND METHODS}

\section{Materials}

Hydroxyl ethyl methacrylate (HEMA), ethylene glycol dimethacrylate (EGDMA), methacrylic acid (MAA), ethyl cellulose $4 \mathrm{cp}$, and Darocur ${ }^{\circledR}(2,4$, 6-trimethyl benzoyldiphenyl-phosphinoxide) were purchased from SigmaAldrich Chemicals (MO, USA). Timolol maleate was received as a gift sample from Zydus Cadila Pharmaceuticals Ltd. (Gujarat, India). Immortalized rabbit corneal epithelial cell lines (Statens Seruminstitut Rabbit Cornea, ATCC ${ }^{\circledR}$
CCL60 ${ }^{\mathrm{TM}}$ ) were purchased from National Centre for Cell Science (Pune, India). Ultra-pure water obtained by reverse osmosis (resistivity $>18.2 \mathrm{M} \Omega \mathrm{cm}$; synergy U.V. Millipore, India) was used throughout the study. All the required chemicals were purchased from Sigma-Aldrich Chemicals (MO, USA).

\section{Preparation of Timolol Loaded Ethyl Cellulose Micro- particles}

Timolol loaded ethyl cellulose microparticles were prepared using spray drying technique. Ethyl cellulose and timolol at various ratios $(50: 50,70: 30$ and $85: 15)$, were mixed and dissolved in ethanol. The clear solutions were spray dried using Mini Spray-dryer (Cronimac, India) to obtain drug dispersed ethyl cellulose microparticles. Applied spraying parameters were: $0.5-\mathrm{mm}$ nozzle, inlet temperatures $80^{\circ} \mathrm{C}$, outlet temperatures $50^{\circ} \mathrm{C}-60^{\circ} \mathrm{C}$, spray-flow $5 \mathrm{~kg} / \mathrm{cm}^{2}$, pumps setting $5 \mathrm{ml} / \mathrm{min}[37,38]$. Batches were coded as EC$50 \%, \mathrm{EC}-70 \%$ and $\mathrm{EC}-85 \%$ for respective ratios of $50: 50$, 70:30 and 85:15 (ethyl cellulose: timolol).

\section{Characterization of Ethyl Cellulose Microparticles}

Dynamic light scattering: The size of Microparticles was determined using Malvern Zetasizer Nano ZS (Model ZEN $3500, \mathrm{WR}, \mathrm{UK})$ at $633 \mathrm{~nm}$. The Zetasizer uses the dynamic light scattering (DLS) principle to determine the particle size, and measurements were made using a detection angle of $90^{\circ}$ [39].

Scanning electron microscope (SEM): To study the surface morphology of the microparticles, samples were analysed by SEM (JSM-6510LV, MA, USA). Silicon substrate $(15 \mathrm{~mm})$ was cleaned ultrasonically in acetone. SEM analysis was executed at $1 \mathrm{kV}$ and magnifications ranging from $4000 \times$ to $12000 \times[40,41]$.

Powder X-ray diffraction (PXRD): PXRD patterns were recorded at room temperature using Bruker's model D8 Advance Diffractometer (Karlsruhe, West Germany) equipped with a compensating slit, using $\mathrm{Cu}-\mathrm{K}$ radiation at $40 \mathrm{kV}$ and $40 \mathrm{~mA}$ passing through nickel filter with divergence slit $\left(0.5^{\circ}\right)$, antiscattering slit $\left(0.5^{\circ}\right)$ and receiving slit $(1 \mathrm{~mm})$. Samples were scanned over a range of $2 \theta$ values from $10^{\circ}$ to $80^{\circ}$ at a scan rate of $0.02^{\circ} \mathrm{sec}^{-1}$ [42]. Average crystallite size of crystal was calculated based on PXRD peak broadening using the Scherrer equation (1).

$\tau=\frac{K \lambda}{\beta_{\tau} \cos \theta}$

Where $\tau$ is the mean crystallite dimension, $\mathrm{K}$ is a constant of $0.9, \lambda$ is the X-ray wavelength $(1.542 \mathrm{~nm}), \beta_{\tau}$ is the peak broadening value due to crystal size reduction, i.e., the fullwidth-at-half-maximal (FWHM) [43].

\section{Preparation Methods}

Composition of pre-monomer mixture: Pre-monomer mixture includes hydroxyl ethyl methylacrylate (HEMA, $46.7 \% \mathrm{w} / \mathrm{w})$ as common contact lens material, methacrylic acid (MAA, 0.8\% w/w), ethylene glycol dimethylacrylate (EGDMA, 0.5\% w/w) as cross-linking agents that add dimensional stability, and water $(52 \% \mathrm{w} / \mathrm{w})$. 
Fabrication of prototype hydrogels: Hydrogels were fabricated by free radical polymerization reaction. $0.5 \% \mathrm{w} / \mathrm{w}$ of Darocur, a photo initiator was mixed with pre-monomer mixture. The mixtures were sonicated for 15 minutes to remove air bubbles and were transferred with help of micropipette $(50 \mu \mathrm{L}$ volume) between two glass plates (mould) separated by teflon spacer $(0.1 \mathrm{~mm}$ thickness). The moulds were then placed in Ultraviolet transilluminator (Ultra Lum, Inc.) and the hydrogels were cured by irradiating UV-B light (365 $\mathrm{nm}$ ) for 30 minutes. The hydrogels were then removed and preserved in desiccators till further use [44].

Direct loading of timolol into hydrogels: Timolol was loaded directly in hydrogels by dissolving timolol into premonomer mixture. Hydrogels were fabricated by the same procedure as described above. Three batches coded DL-50, DL-100, and DL-150 were prepared by adding $0.01 \%$, $0.02 \%$, and $0.03 \% \mathrm{w} / \mathrm{w}$ of timolol in pre-monomer mixture respectively. Each $50 \mu \mathrm{L}$ volume of hydrogels was loaded with timolol, as shown in Table $\mathbf{1}$.

Table 1. Details of timolol laden hydrogels by direct loading method.

\begin{tabular}{|c|c|c|}
\hline Coding & $\begin{array}{c}\text { Timolol concentration in } \\
\text { pre monomer mixture } \\
(\mathbf{\%} \mathbf{w} / \mathbf{w})\end{array}$ & $\begin{array}{c}\text { Loading of timolol in } \\
\text { each 50 } \boldsymbol{\mu} \mathbf{L} \text { hydrogel } \\
(\boldsymbol{\mu g})^{\mathbf{a}}\end{array}$ \\
\hline \hline DL-50 & 0.01 & $52.54 \pm 3.23$ \\
\hline DL-100 & 0.02 & $101.55 \pm 4.67$ \\
\hline DL-150 & 0.03 & $153.75 \pm 4.77$ \\
\hline
\end{tabular}

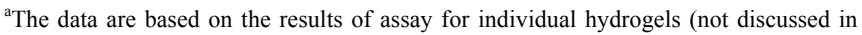
this paper). Values are mean \pm standard deviation $(n=6)$.

Entrapment of timolol loaded ethyl cellulose microparticles into hydrogels: The microparticles laden hydrogels were fabricated by procedure as described above. To entrap timolol loaded microparticles in hydrogels, required amount of microparticles $0.2 \%, 0.33 \%$ and $0.66 \% \mathrm{w} / \mathrm{w}$ were added into pre monomer mixture for respective batches coded EC$50 \%$, EC- $70 \%$ and EC- $85 \%$, to achieve $50 \mu \mathrm{g}$ of timolol loading in each $50 \mu \mathrm{L}$ hydrogels.

\section{Timolol Estimation by HPLC}

Timolol was quantified using HPLC (Shimadzu, CA, USA). The separation column was Grace Smart ${ }^{\mathrm{TM}} \mathrm{C}_{18}$ reverse-phase column $(4.6 \times 250 \mathrm{~mm}, 5$ micron, California, USA), maintained at $40^{\circ} \mathrm{C}$. The mobile phase was a mixture of phosphate buffer ( $\mathrm{pH} 2.8)$ and methanol (65:35 v/v). The flow rate was fixed at $1 \mathrm{ml} / \mathrm{min}$ and the detection wavelength was set at $295 \mathrm{~nm}$. The retention time for timolol under these conditions was $3.75 \mathrm{~min}$. The standard curve of timolol in tear fluid was linear over the concentration range from 1-5 $\mu \mathrm{g} / \mathrm{ml}\left(\mathrm{R}^{2}=0.999\right)[45,46]$.

\section{Characterization of Hydrogels}

Transmittance: Optical property of hydrogel contact lenses should not change after loading timolol and microparticles in the hydrogels. The hydrogel sheets were hydrated by soaking in simulated tear fluid for 24 hours, and mounted in a quartz cuvette. The cuvette was placed in a UV-Vis spectrophotometer and at $630 \mathrm{~nm}$ transmittance was measured [47].

Swelling study: Swelling study is important in case of hydrogel contact lenses, as degree of hydration governs dimensions, oxygen permeability, transmittance and release rate of drug. Swelling study was conducted by placing hydrogels in simulated tear fluid at room temperature for 24 hrs. The hydrogels were removed from the solution, patted dry with a soft tissue paper, and weighed in air using a sensitive weighing balance. Initial dry weights of hydrogels were calculated directly after removing from the mold.

$\%$ Swelling $=\frac{\text { Weight of fully swollen hydrogel-Weight of dry hydrogel }}{\text { Weight of dry hydrogel }}$

$\mathrm{Na}^{+}$Ion permeability: Extended wear contact lenses must be permeable to ions to ensure homeostasis of ion concentration in the post lens tear film, which is necessary for lens motion. It has been reported that extended wear contact lenses must possess ion permeability greater than $1.5 \times 10^{-6}$ $\mathrm{mm}^{2} / \mathrm{min}$ [39]. The ionic permeability of timolol and microparticles laden hydrogels was determined by experiment, in which hydrogel sheet was attached to the bottom of the donor chamber filled with $5 \mathrm{ml}$ of $0.1 \mathrm{M} \mathrm{NaCl}$ solution. Donor chamber consisted of a tube of $5 \mathrm{~mm}$ inner diameter, which was placed in a receiving chamber containing $50 \mathrm{ml}$ of deionized water. The receiving chamber was placed on a magnetic stirring plate thermostatized at $35^{\circ} \mathrm{C}$ to simulate physiological conditions. The conductivity of receptor solution was monitored as a function of time using a conductivity meter and subsequently converted to $\mathrm{NaCl}$ concentration using the calibration plot. The conductivity probe was calibrated before each measurement experiment, using different $\mathrm{NaCl}$ solutions of known concentration ranging $1 \mu \mathrm{g} / \mathrm{ml}$ to $14 \mu \mathrm{g} / \mathrm{ml}$. By plotting concentration of $\mathrm{Na}^{+}$ions in receiving chamber versus time, the apparent $\mathrm{Na}^{+}$ion permeability was calculated from the slope, using equation (3).

$C_{R}=\frac{A P C_{L, 0}}{V_{R} L}\left(t-t_{0}\right)$

Where $\mathrm{C}_{\mathrm{R}}$ is the concentration of $\mathrm{Na}^{+}$ions at time $t$ in the receiving chamber, $\mathrm{C}_{\mathrm{L}, 0}$ is the initial concentration of $\mathrm{Na}^{+}$ ions in donor chamber, $\mathrm{A}$ is the area of the lens exposed to the salt flux, L represents the average hydrogel thickness in the area exposed, $V_{R}$ is the volume of the receiving chamber compartment and $\mathrm{P}$ is the apparent permeability coefficient of $\mathrm{Na}^{+}$ion [48].

Dynamic contact angle measurement: Contact angle was determined to evaluate the effect of timolol and microparticles on change in hydrophilicity of hydrogels (surface wettability) $[49,50]$. Dynamic contact angle of Milli Qwater on timolol and microparticles laden dry hydrogels were determined using Theta Optical Goniometer (Attension, KSV Instrument, USA). Hydrogel sheet was placed on sample stage and with the help of Hamilton syringe a drop of Milli Q-water was placed on the surface of dry hydrogel. The captured image of drop was continuously analysed to measure the angle formed between the dry sheet and the tangent surface.

Drug release rate: Direct loaded and timolol loaded microparticles laden hydrogels were placed in $2 \mathrm{ml}$ of simulat- 
ed tear fluid in glass vial, and kept at $35^{\circ} \mathrm{C}$ in incubator with shaker at 100 RPM. The volume of the release medium was chosen to be $2 \mathrm{ml}$ to approximately match the in vivo conditions of daily tear turnover. The simulated tear fluid was replaced at every interval with the same volume of fresh simulated tear fluid, to maintain perfect sink condition. The content of timolol was determined by HPLC at $295 \mathrm{~nm}$ after suitable dilution. The release profile of timolol was evaluated by plotting graphs of cumulative drug release $(\mu \mathrm{g})$ versus time, percentage drug release versus time and release rate (ng/hr) versus time. The experiments were carried out in triplicate [51].

Mathematical model for diffusion coefficient and release kinetics: To determine the diffusion coefficient of timolol from hydrogels, the hydrogel sheet was assumed to be shaped like a slab [52]. The amounts released were fitted to equation (4) for short time $\left(\mathrm{Mt} / \mathrm{M}_{\infty}<0.65\right)$, of drug release profile.

$\frac{\mathrm{M}_{\mathrm{t}}}{\mathrm{M}_{\infty}}=4\left[\frac{\mathrm{Dt}}{\pi \mathrm{L}^{2}}\right]^{1 / 2}$

By plotting the fractional release of timolol versus $\left(\mathrm{t}^{0.5} / \mathrm{L}\right)$, the diffusion coefficient was calculated from the slope. To evaluate how well the data matched with a Fickian release profile, the empirical Power Law equation (5) was used [53].

$\frac{\mathrm{M}_{\mathrm{t}}}{\mathrm{M}_{\infty}}=\mathrm{kt}^{\mathrm{n}}$

$\log \frac{\mathrm{M}_{\mathrm{t}}}{\mathrm{M}_{\infty}}=\mathrm{k}+\mathrm{n} \log (\mathrm{t})$

Using the data of timolol release profiles and by plotting graph of $\log \left(\mathrm{Mt} / \mathrm{M}_{\infty}\right)$ versus $\log (\mathrm{t})$, the diffusional exponent (n) was calculated from the slope and intercept k. By determining the diffusional exponent (n), the information about the physical mechanism controlling timolol release from a hydrogel was gain.

Estimation of therapeutic dose: For treatment of glaucoma the recommended dosage for $0.125 \% \mathrm{w} / \mathrm{v}$ solution of timolol eye drops is 1 drop 2 times daily. The volume of a typical eye drop is $50 \mu \mathrm{L}$. Thus a drop delivered two times a day would deliver $125 \mu \mathrm{g}$ of timolol/day. The bioavailability of timolol delivered through eye drops is only about $5 \%$, which implies that the therapeutic requirement of timolol from hydrogel contact lens is about $12.5 \mu \mathrm{g} /$ day or 520 ng/hour (considering 50\% bioavailability from contact lens) $[39,52]$.

\section{Cytotoxicity Study}

Cytotoxicity study was conducted to check if the leachable extract from the microparticles laden hydrogels show any local toxicity. Immortalized rabbit corneal epithelial cell lines (Statens Seruminstitut Rabbit Cornea, ATCC ${ }^{\circledR}$ CCL60 ${ }^{\mathrm{TM}}$ ) were purchased from National Centre for Cell Science (NCCS), Pune, India. Corneal epithelial cells were suspended in culture media $\left(1 \times 10^{5}\right.$ cells $\left./ \mathrm{ml}\right)$ and seeded into 24 -well plates $(500 \mu$ culture medium in each well). Culture medium includes Eagle minimum essential medium supplemented with $10 \%$ fetal calf serum, $100 \mu \mathrm{g} / \mathrm{ml}$ penicillinstreptomycin buffered with sodium bicarbonate, incubated at
$5 \% \mathrm{CO}_{2}, 37^{\circ} \mathrm{C},>90 \%$ humidity for $24 \mathrm{~h}(\sim 1$ doubling period) to form a semi-confluent monolayer. Culture medium was aspirated from the cells, and added per well, $500 \mu \mathrm{l}$ of medium containing test extract (test extract was prepared in culture medium itself), or the negative control (without test extract), or the positive control $(0.01 \mathrm{mg} / \mathrm{ml}$ Sodium Lauryl sulphate) and incubated for 24 hours $\left(5 \% \mathrm{CO}_{2}, 37^{\circ} \mathrm{C},>90 \%\right.$ humidity). Commercially available methafilcon contact lenses (Bausch and Lomb, USA) composed of the same hydrogel material were purchased and used in study for comparison. After $24 \mathrm{hrs}$ of incubation, cell viability was assessed using MTT dye (colorimetric assay). A volume of $50 \mu \mathrm{l}$ of the MTT solution $(0.5 \mathrm{mg} / \mathrm{ml})$ was added to each test well and the plates were further incubated for $2 \mathrm{hrs}$ in the incubator at $37^{\circ} \mathrm{C}$. Formazan salt was solubilized in DMSO and absorbance was measured at $540 \mathrm{~nm}$ using MTT dye. Results are reported as mean \pm standard deviation of measured absorbance normalized to the absorbance for nontreated control cells using equation (6). If viability is reduced to $<70 \%$ of the negative control, it has a cytotoxic potential $[54,55]$.

Cell viability $(\%)=\frac{A_{\text {sample }}}{A_{\text {control }}} \times 100$

\section{Statistical Analysis}

Statistical analyses was carried out using t-test, analysis of variance (ANOVA) and the Tukey LSD test using SPSS programs (Version 21.0 for Window ${ }^{\circledR}$, Chicago, IL).

\section{RESULTS AND DISCUSSION}

\section{Characterization of Ethyl Cellulose Microparticles}

Average particle size of batch EC-50\%, EC-70\% and EC$85 \%$ was found to be $4.33 \mu \mathrm{m}, 4.82 \mu \mathrm{m}$ and $4.59 \mu \mathrm{m}$ respectively, which is in agreement with SEM report. The results clearly suggest that the particle size is uncorrelated to the amount of timolol loaded, and is instead controlled by the spray drying parameters (data not shown).

Surface morphology of timolol, ethyl cellulose and timolol loaded microparticles were studied by SEM (Fig. 1). In case of timolol, droplets of irregular shape were observed. Ethylcellulose was found to be porous and irregular in shape with nearly $200-1000 \mu \mathrm{m}$ in size. SEM of microparticles for all three batches showed uniform spherical shaped porous (cavity) micron size particles $(3-7 \mu \mathrm{m})$.

The XRD pattern of timolol, ethylcellulose and timolol loaded ethyl cellulose microparticles are shown in Fig. (2). The XRD scan of timolol showed number of intense peaks of crystallinity (highest peak at $2 \theta=19.47$, intensity $=4054$ ); whereas the XRD pattern of microparticles exhibited a reduction in both number and intensity of peaks, indicating decrease in crystallinity and uniform dispersion of drug in ethylcellulose microparticles. The relative degree of crystallinity (RDC) was determined by comparing the representative peak height at 19.47 Pos. [2 $\theta$ ] in the diffraction patterns of drug with those of drug loaded microparticles. The relationship used for the calculation of degree of crystallinity was $(\mathrm{RDC})=\mathrm{I}_{\mathrm{p}} / \mathrm{I}_{\text {drug }}$, where $\mathrm{I}_{\mathrm{p}}$ is the peak height of microparticles under investigation and $\mathrm{I}_{\text {drug }}$ is the peak height at the 

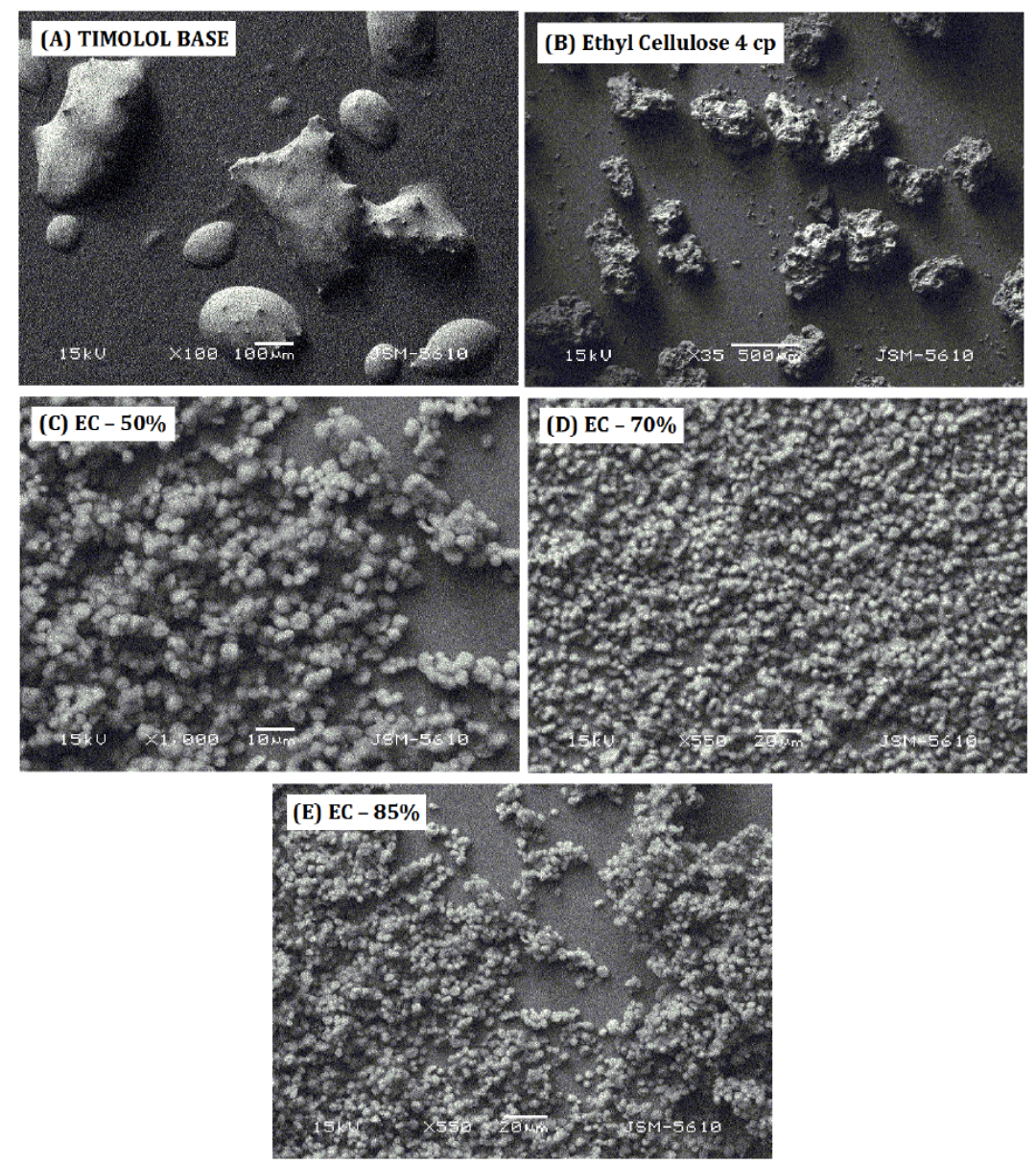

Fig. (1). SEM report of (A) Timolol base, (B) Ethyl cellulose, (C) EC-50\%, (D) EC-70\%, (E) EC-85\%.

same angle for the drug with the highest intensity [40, 5658]. The RDC for all samples are shown in Table 2. The order of reduction in the crystallinity is as follows: EC-50\% $>$ EC-70\% $>$ EC- $85 \%$. Also we can observe that, as the amount of ethyl cellulose increases, the crystallite size of drug reduces, indicating a better dispersion of drug in polymer. The change in d-spacing values indicates the doping of drug in planes of ethylcellulose $\left(4.398 \mathrm{~A}^{\circ}\right)$.

\section{Transmittance}

The $\%$ transmittance of hydrogels is important in its application as contact lenses for clear vision. Statistical results indicated that the direct drug laden hydrogels showed nonsignificant $(\mathrm{P}>0.05)$ decrease in \% transmittance (Table 3 ). Thus, transmittance was not affected in case of direct loading of timolol in hydrogels. The $\%$ transmittance was significantly reduced $(\mathrm{p}<0.05)$, below $90 \%$ for microparticles laden batches. The impact was directly proportional to amount of microparticles loaded in hydrogels. There was no change in $\%$ transmittance, if amount of timolol in microparticles was varied (data not shown). The reduction in transmittance of hydrogel is due to larger particle size (4 to 5 microns); this problem can be resolved by reducing the particle size to nano level to improve visual properties. Thus the presence of hydrophobic ethylcellulose microparticles reduced the visual clarity of hydrogels, which is not good enough for contact lens use.

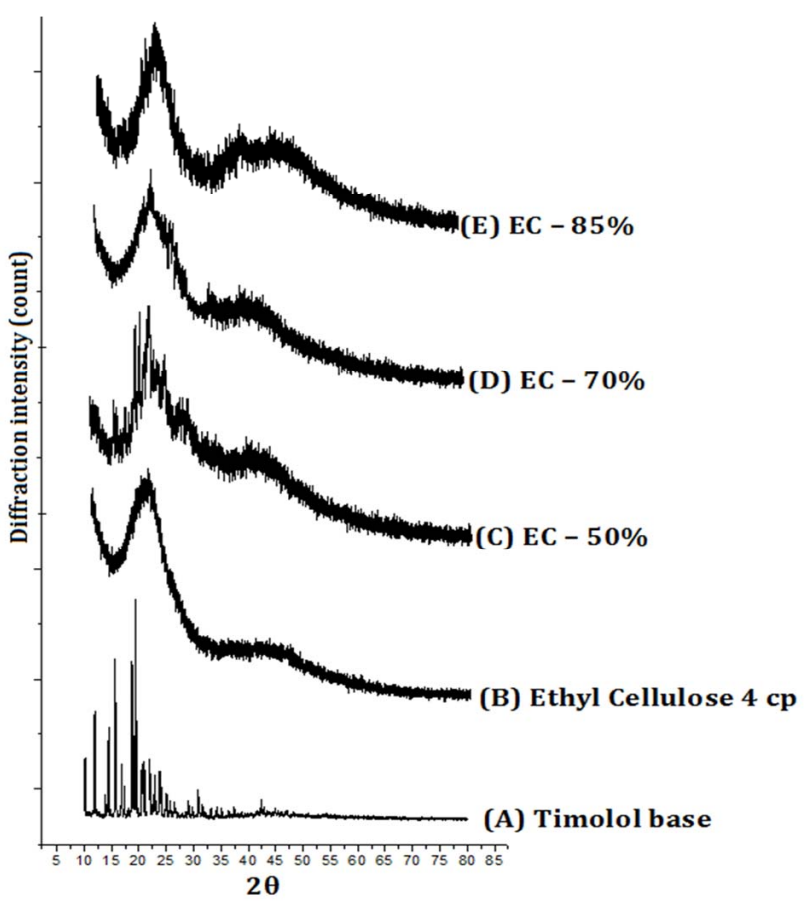

Fig. (2). Powder XRD Pattern of (A) Timolol base, (B) Ethyl cellulose, (C) EC-50\%, (D) EC-70\%, (E) EC-85\%. 
Table 2. Results of powder XRD.

\begin{tabular}{|c|c|c|c|c|}
\hline Type of system & $\begin{array}{c}\text { d-spacing }[\AA] \text { at } 20.17 \text { [20] } \\
\text { of Ethylcellulose }(4 \mathrm{cP})\end{array}$ & $\begin{array}{c}\text { Intensity [cts] at } \\
19.47[2 \theta]\end{array}$ & RDC & $\begin{array}{l}\text { Crystallite } \\
\text { Size (nm) }\end{array}$ \\
\hline Timolol base & - & 4054 & - & 671.77 \\
\hline Ethylcellulose (4 cP) & 4.398 & - & - & - \\
\hline EC $-50 \%$ & 4.134 & 1283 & 31.67 & 250.56 \\
\hline $\mathrm{EC}-85 \%$ & 4.309 & 621 & 15.31 & 9.4 \\
\hline
\end{tabular}

Table 3. Physical properties of hydrogel sheets.

\begin{tabular}{|c|c|c|c|}
\hline Hydrogel type & Transmittance (\%) & Swelling (\%) & $\begin{array}{l}\mathrm{Na}^{+} \text {ion permeability } \\
{\left[\mathrm{P}_{\text {ion }} \times 10^{-6}\left(\mathrm{~mm}^{2} / \mathrm{min}\right)\right]}\end{array}$ \\
\hline Blank sheet & $98.3 \pm 0.05$ & $78.50 \pm 0.99$ & $6.38 \pm 0.19$ \\
\hline DL-50 & $98.1 \pm 0.10$ & $77.61 \pm 1.10$ & $5.75 \pm 0.25$ \\
\hline DL-100 & $97.6 \pm 0.08$ & $76.49 \pm 1.39$ & $5.14 \pm 0.37$ \\
\hline EC- $50 \%$ & $86.9 \pm 0.25$ & $76.30 \pm 0.84$ & $4.16 \pm 0.61$ \\
\hline EC- $70 \%$ & $78.8 \pm 0.55$ & $70.72 \pm 0.78$ & $3.76 \pm 0.35$ \\
\hline EC- $85 \%$ & $62.4 \pm 0.70$ & $62.82 \pm 0.84$ & $2.06 \pm 0.57$ \\
\hline
\end{tabular}

\section{Swelling}

Swelling study is critical in case of hydrogel contact lenses, as degree of hydration governs dimensions, ion permeability, oxygen permeability, and release of drug from contact lens. The data of \% swelling are shown in Table 3. The \% swelling was slightly decreased with increase in timolol in direct timolol loaded batches. Statistical analysis results showed no significant difference $(\mathrm{P}>0.05)$ in \% swelling between the blank hydrogel and direct timolol loaded hydrogels. In case of timolol loaded ethylcellulose microparticles laden hydrogels, the \% swelling was expected to decrease due to negligible water uptake by hydrophobic microparticles. Statistical analysis results showed significant decrease $(\mathrm{P}<0.05)$ in \% swelling between the blank hydrogels and microparticles laden hydrogels. Also \% swelling decreases as the amount of microparticles increases (from Batch EC-50\% to EC-85\%). Thus the optimization of the amount of microparticles in hydrogel is prerequisite to study, so that the $\%$ swelling do not affects the dimension and other vital properties of contact lens.

\section{$\mathrm{Na}^{+}$Ion Permeability}

Adequate $\mathrm{Na}^{+}$ion permeability is required to prevent abrasion of contact lens to the eye by forming a fluid hydrodynamic boundary layer between the contact lens and the cornea. According to Nicolson, the minimum requirement for $\mathrm{Na}^{+}$ion permeability $\left(\mathrm{P}_{\text {ion }}\right)$ should be $1.5 \times 10^{-6} \mathrm{~mm}^{2} / \mathrm{min}$. The experimental values of apparent $\mathrm{Na}^{+}$ion permeability were obtained from equation (3) following the experimental procedure described in method. The values of apparent $\mathrm{Na}^{+}$ ion permeability for all the hydrogels are listed in Table 3 . The values of $\mathrm{Na}^{+}$ion permeability for direct timolol loaded batches decreased significantly $(\mathrm{p}<0.05)$ in comparison to blank hydrogels, which could be due to the presence of hydrophobic timolol base.

Furthermore $\mathrm{Na}^{+}$ion permeability for microparticles laden batches decreased significantly $(\mathrm{P}>0.05)$ with increase in microparticles loading (from batch $\mathrm{EC}-50 \%$ to $\mathrm{EC}-85 \%$ ), in comparison to blank hydrogels i.e., the presences of hydrophobic drug and ethyl cellulose microparticles in hydrogels interfere with $\mathrm{Na}^{+}$ion permeability. Though the values are above minimum requirement, i.e. $1.5 \times 10^{-6} \mathrm{~mm}^{2} / \mathrm{min}$, to assure that the contact lenses prepared from such hydrogel materials would not cause abrasion to cornea upon insertion.

\section{Dynamic Surface Contact Angle Measurement}

Wettability of contact lens is an important property related to the wearing comfort for user. Wetting behavior was predicted by measuring the dynamic surface contact angle formed by a drop of Milli Q water on the surface of dry hydrogel sheet [50]. The change in hydrophilicity of the surface of dried hydrogels after incorporating timolol and microparticles were evaluated through contact angle measurements. Dynamic contact angles $(\theta)$ of Milli Q-water on timolol and microparticles laden hydrogel sheets are presented in Fig. (3). In direct timolol loading batches, there is small increase in contact angle at initial 10 seconds with increase in timolol loading. Statistical results indicated insignificant $(p>$ 0.05 ) increased in contact angle in comparison to bank hydrogels. Thus the presence of hydrophobic timolol base did 


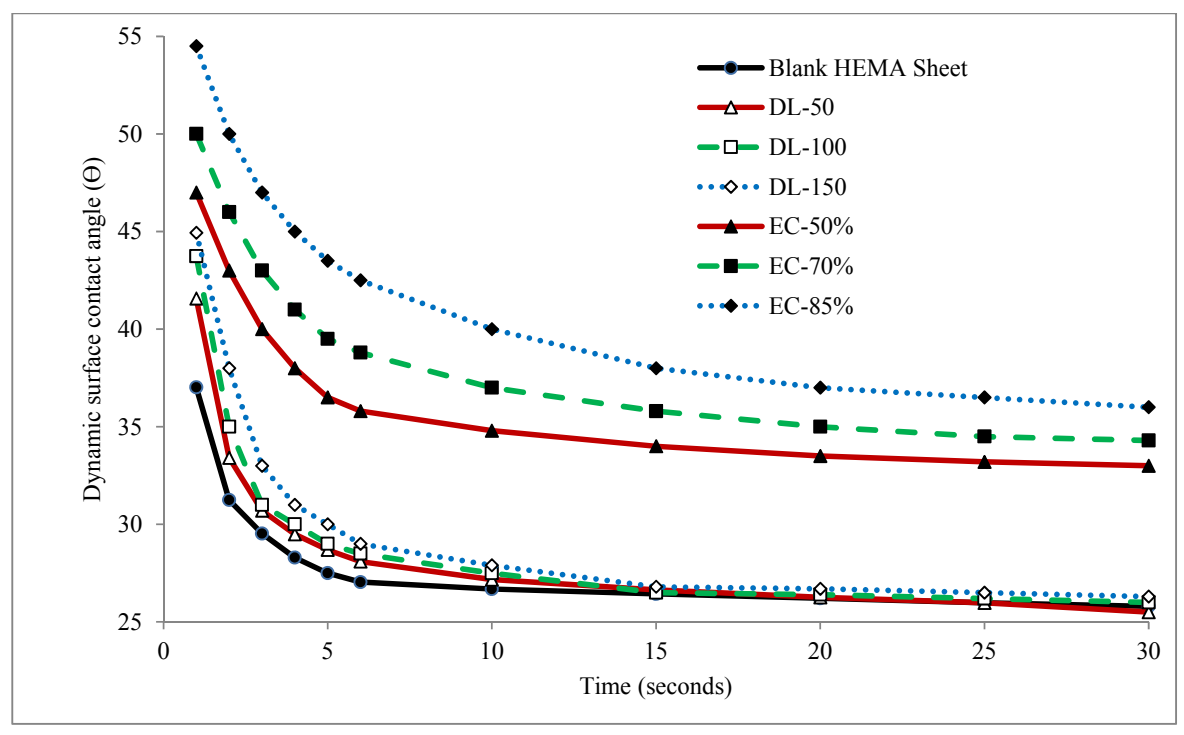

Fig. (3). Dynamic surface contact angle of Milli Q-water on blank and formulation laden dry hydrogels.

not affect the wetting behavior of hydrogels significantly, which was also supported by the results of swelling, and transmittance. For microparticles laden dry hydrogels, a significant increased $(p<0.01)$ in contact angle was observed in comparison to blank and direct timolol loaded hydrogels. Contact angle was also increased with amount of microparticles in hydrogels (from $0.2 \%$ to $0.66 \% \mathrm{w} / \mathrm{w}$ for respective batches EC-50\% to EC-85\%). The results confirmed that the hydrophobic polymer ethylcellulose do play a significant role in decreasing the wettability of hydrogels likewise swelling, transmittance and ion permeability behavior. Therefore the optimal level of microparticles in hydrogel is required, so that it does not affect the vital properties of contact lens for comfort use. Although there is an increase in contact angle in the presence of the microparticles, the value is still below $90^{\circ}$, so the surface is still hydrophilic in nature. The results suggest that, we need to hydrate the hydrogels for longer duration of time for complete hydration before use.

\section{Drug Release Rate}

\section{Release Rate of Drug from Timolol Laden Hydrogels Pre- pared by Direct Loading Method}

Conventional methodology of direct drug loading was achieved by adding timolol base directly into pre-monomer mixture (direct loading), before fabrication. Three hydrogels coded DL-50, DL-100 and DL-150 were analysed, which contain $50 \mu \mathrm{g}, 100 \mu \mathrm{g}$, and $150 \mu \mathrm{g}$ of drug respectively (in each $50 \mu \mathrm{L}$ volume of hydrogel). The cumulative $(\mu \mathrm{g})$ and percentage drug release profiles are shown in Figs. (4 and $\mathbf{5})$ respectively.

All three batches showed a burst release (43-45\%) at first hour (Fig. 5), indicating rapid diffusion of drug from the aqueous channels of hydrogel matrix. This could be due to partial solubility of timolol in tear fluid $(2.74 \mathrm{mg} / \mathrm{ml})$ and absence of controlling membrane. The cumulative drug release profiles suggest that the amount of drug released depends on the drug loading in hydrogels, while percentage drug release from hydrogels with time is independent of the amount of drug loaded (non-significant, $p>0.05$ ). All the hydrogels under study displayed the same general pattern of drug release profiles. Release rate of timolol within the therapeutic level (520 ng/hour) for DL-50, DL-100 and DL-150 batches were found to be 14,15 and 22 hours respectively (Table 4, Fig. 6). Thus with direct loading methodology release up to 22 hours is possible, with limitation of high burst release and high drug loading.

To understand the mechanism of drug release, it was imperative to compare the short span release profiles $(65 \%$ release) with diffusion controlled models. Release profiles were fitted to equation 4 and 5 to give diffusion coefficient values, release exponent $\mathrm{n}$ and intercept $\mathrm{k}$ as shown in Table 4. The calculated diffusion coefficients (Average thickness of sheet $=0.47 \mathrm{~mm}$ ) for batches DL-50, DL-100 and DL-150 were $2.36 \times 10^{-7}, 3.31 \times 10^{-7}$, and $3.44 \times 10^{-7}$ $\mathrm{mm}^{2} / \mathrm{sec}$ and the diffusional exponent (n) was found to be $0.212,0.257$ and 0.263 respectively. Diffusion coefficient values actually increases with increase in timolol loading, suggesting no added advantage of increased in drug loading for sustained drug delivery. The diffusional exponents $(\mathrm{n}<$ 0.5 ) signpost diffusion controlled fickian release of timolol from hydrogels for all three batches. Higher values of intercept $\mathrm{k}$, indicate low affinity of timolol with hydrogel polymer matrix, and no change ( $>0.05)$ in $\mathrm{k}$ values indicate that there is no change in affinity between timolol and hydrogel polymer matrix with increased in drug loading.

\section{Drug Release Rate}

\section{Drug Release from Timolol Loaded Ethyl Cellulose Micro- particles Laden Hydrogels Prepared by Spray Drying Method}

Three batches EC-50\%, EC-70\%, and EC-85\% containing $50 \mu \mathrm{g}$ of timolol in each $50 \mu \mathrm{L}$ volume of hydrogels were analysed. The cumulative $(\mu \mathrm{g})$ and percentage release profiles are shown in Figs. (7 and 8) respectively. Ethyl cellulose content in microparticles increases from $50 \%$ to $85 \%$ for 


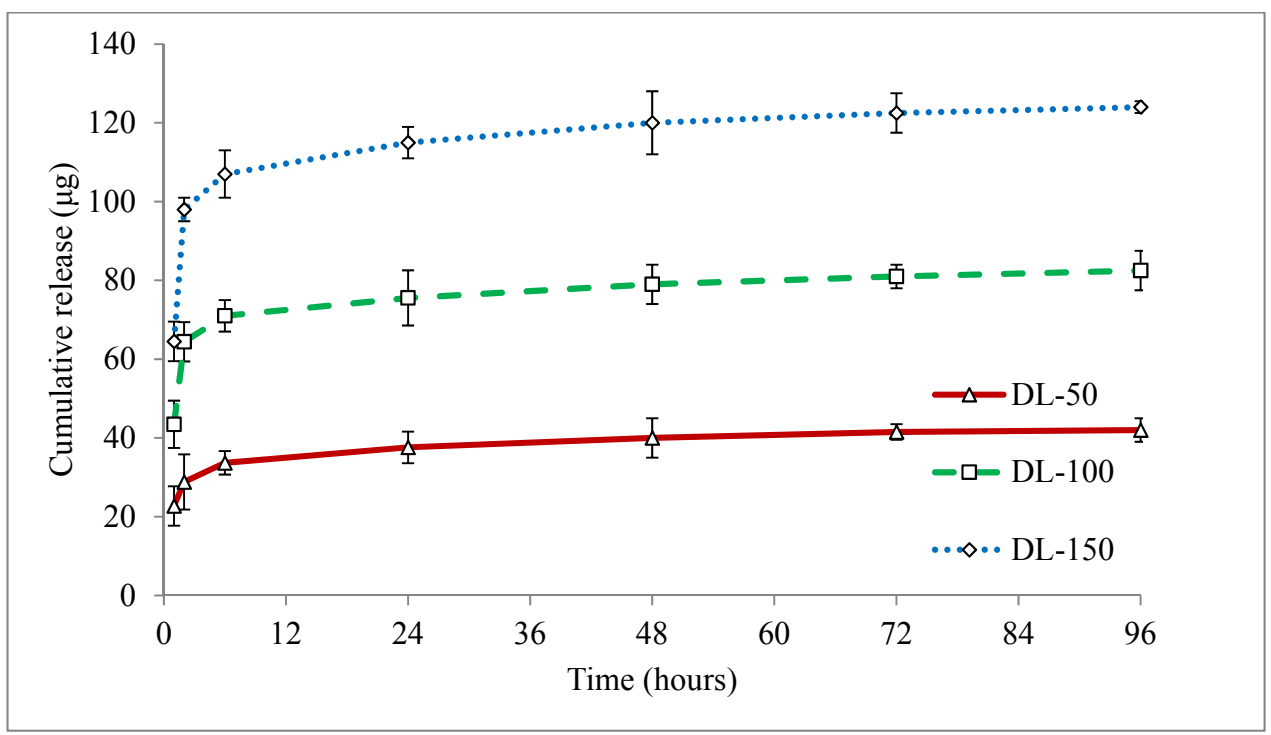

Fig. (4). Cumulative release of timolol from hydrogels prepared by direct loading method. The total mass of timolol loaded into hydrogel sheets were 50,100, and $150 \mu \mathrm{g}$ for the batches DL-50, DL-100, and DL-150 respectively. Values are shown as mean \pm standard deviation $(n=6)$.

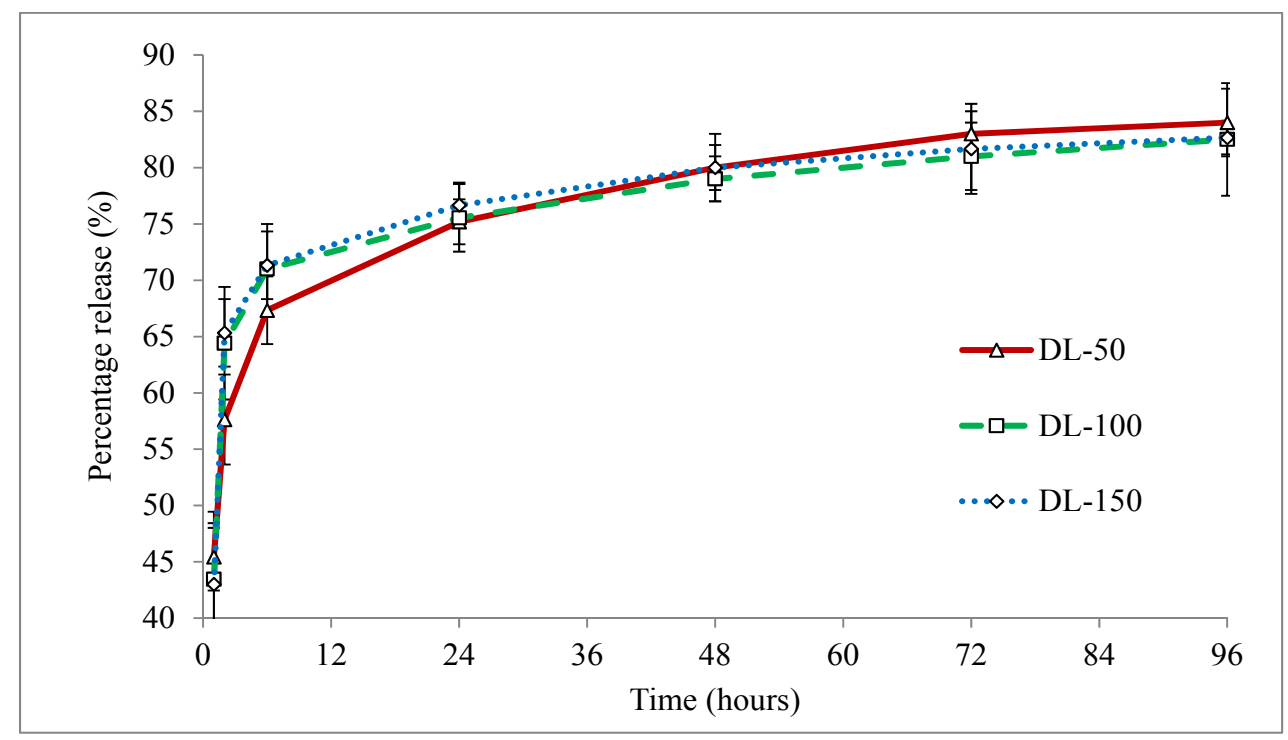

Fig. (5). Percentage release profile of timolol loaded hydrogels prepared by direct loading method. Values are shown as mean \pm standard deviation $(n=6)$.

Table 4. Drug release kinetics data of direct loaded and timolol loaded ethyl cellulose microparticles laden hydrogels.

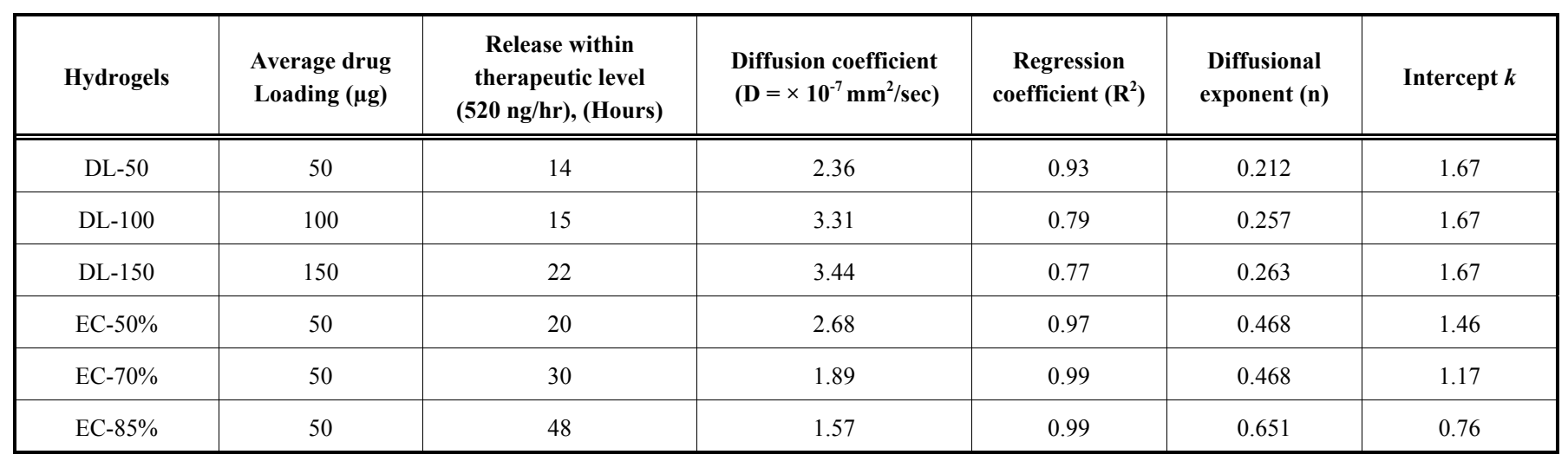




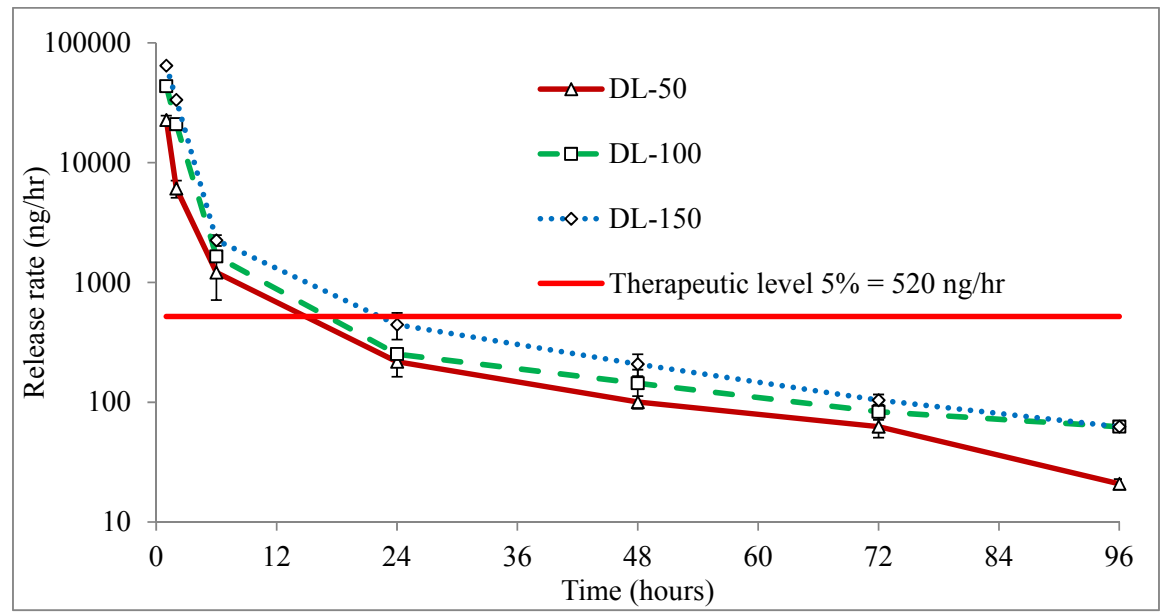

Fig. (6). Release rate (ng/hr) of timolol per hour from hydrogels prepared by direct loading method, using cumulative release data. Data are shown as mean \pm standard deviation $(n=6)$. \#Therapeutic release rate required for contact lenses were calculated according to $5 \%$ absorption from eye drops.

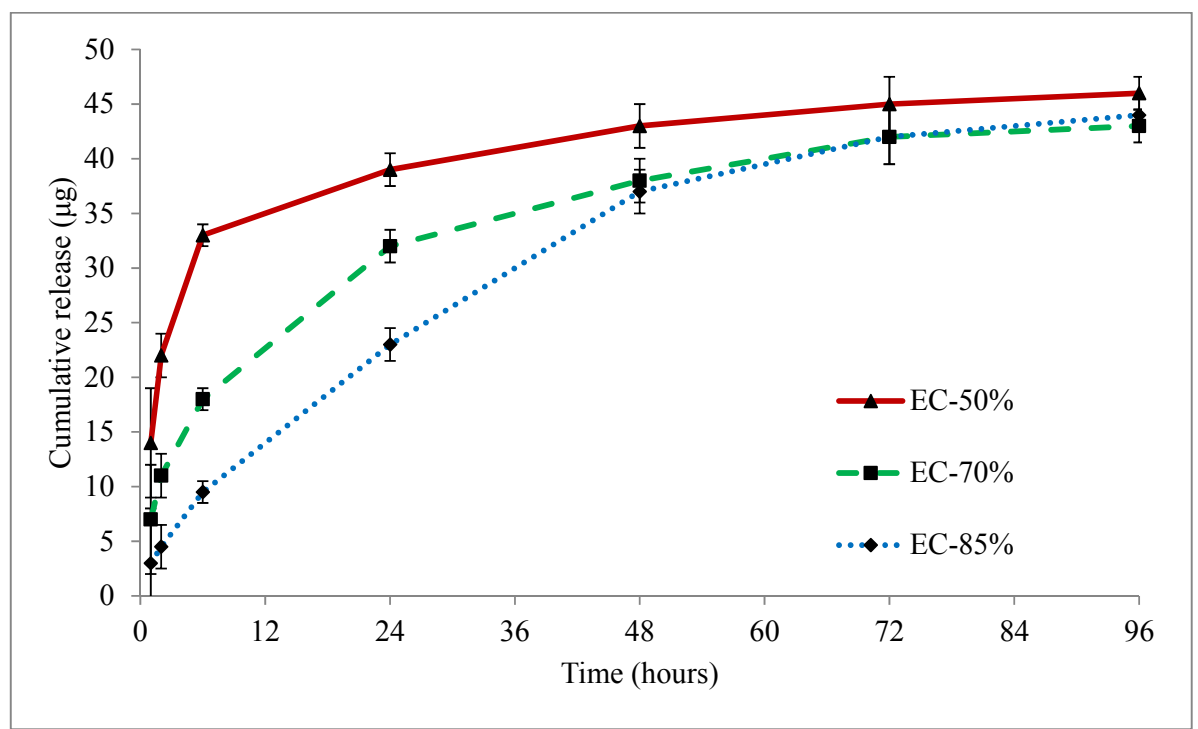

Fig. (7). Cumulative release of timolol from ethyl cellulose laden hydrogels prepared by spray drying method. The total mass of timolol loaded into hydrogel sheets were $50 \mu \mathrm{g}$. Values are shown as mean \pm standard deviation $(\mathrm{n}=6)$.

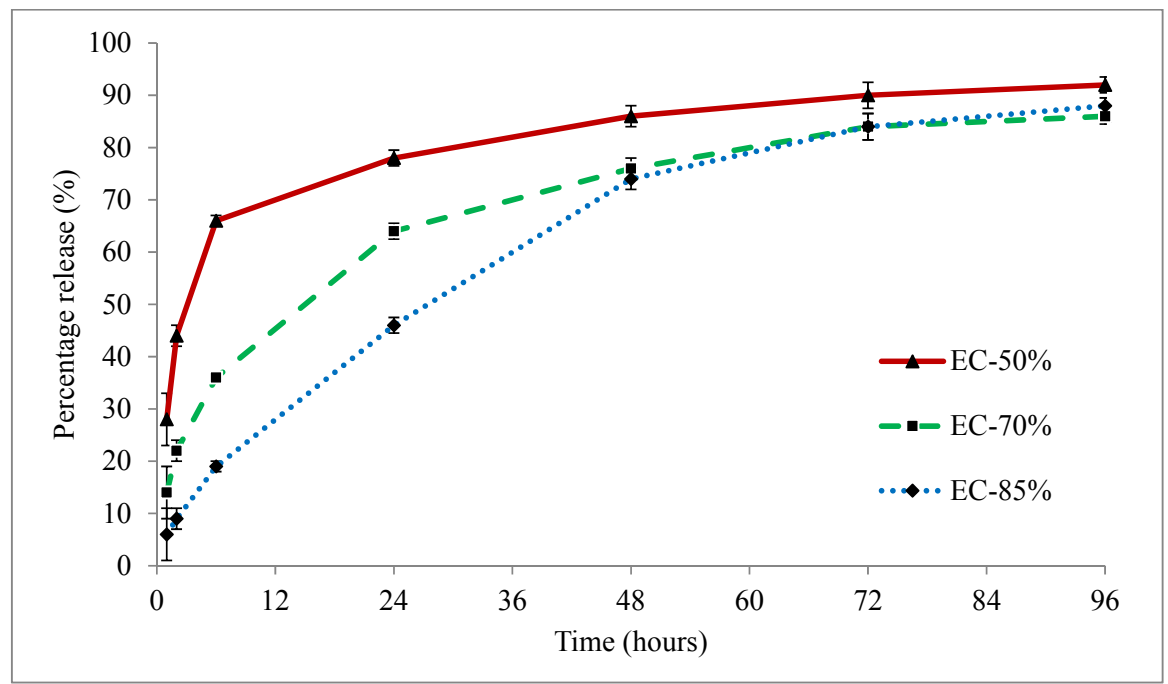

Fig. (8). Percentage release profile of timolol from ethyl cellulose laden hydrogels prepared by spray drying method. Values are shown as mean \pm standard deviation $(n=6)$. 


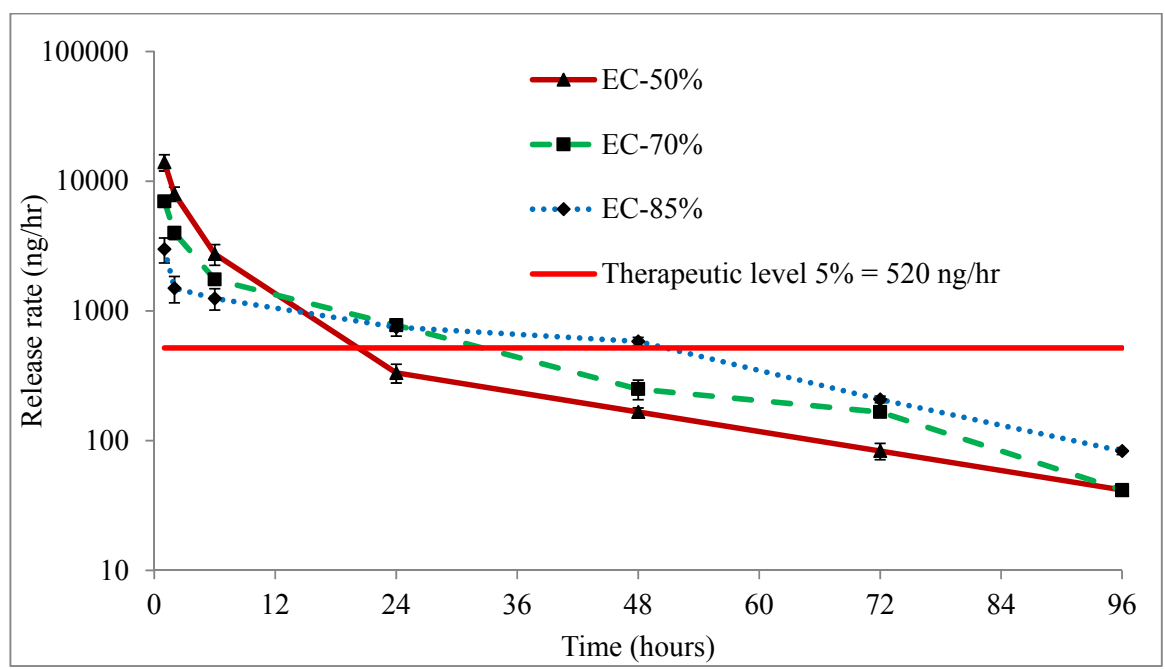

Fig. (9). Release rate (ng/hr) of timolol per hour from hydrogels prepared by spray drying method, using cumulative release data. Data are shown as mean \pm standard deviation $(n=6)$. Therapeutic release rate required for contact lenses were calculated according to $5 \%$ absorption from eye drops.

respective batches EC-50\% to EC-85\%. Release profile curves indicated that as the amount of ethyl cellulose in microparticles increases, initial burst release reduces showing more sustained release of drug. Thus, the percentage release of timolol from hydrogel with time is dependent $(\mathrm{P}<0.05)$ on the amount of ethyl cellulose in microparticles. A significant enhancement $(\mathrm{p}<0.01)$ in release rate duration was observed (Fig. 9), from batch EC-50\% to EC-85\%. Release rate of timolol within the therapeutic level $(520 \mathrm{ng} / \mathrm{hr})$ for EC-50\%, EC-70\%, and EC-85\% batches were found to be 20 hrs, $30 \mathrm{hrs}$ and $48 \mathrm{hrs}$ respectively (Table 4).

The mechanism of drug transport from microparticles laden hydrogel to release media is highly complex, potentially involving drug diffusion, drug dissolution, drug-polymer chain interactions, time-dependent drug permeability within the polymeric matrix, etc [39]. The possible barrier involved in restricting the drug release could be the long tortuous pathway created by the matrix of ethylcellulose. Also higher the amount of ethylcellulose in microparticles, longer the pathway and more sustained release observed (EC-85\% batch). The microparticles laden hydrogels showed sustained release even with low drug loading of $50 \mu \mathrm{g}$ in comparison to direct loading batches (50-150 $\mu \mathrm{g})$. Thus the results clearly suggest the potential of ethyl cellulose microparticles in sustaining the drug release duration.

Diffusion coefficient for EC-50\%, EC-70\%, and EC-85\% batches were found to be $2.68 \times 10^{-7}, 1.89 \times 10^{-7}$ and $1.57 \times$ $10^{-7} \mathrm{~mm}^{2} / \mathrm{sec}$ and the diffusional exponents (n) $0.468,0.468$, and 0.651 respectively (Table 4). Diffusion coefficient differ significantly $(\mathrm{p}<0.01)$ in comparison to direct drug loaded hydrogels. Diffusion of drug from hydrogel decreased with increase in amount of ethyl cellulose in microparticles. The diffusional exponents for EC-85\% batch, signpost that we successfully achieved zero order release kinetics. Lower values of intercept $\mathrm{k}$ in comparison to direct drug loaded hydrogels $(p<0.05)$; clearly suggest a very strong affinity of timolol with ethyl cellulose in hydrogel matrix. Also the affinity significantly increases $(\mathrm{p}<0.01)$ with increase in ethyl cellulose in microparticles. The results suggest that increase in ethyl cellulose content in microparticles, increases the drug release duration from hydrogel, while at the same time affecting the physical and optical property of hydrogels. The results propose significant improvement in release duration (sustained release) with timolol loaded ethyl cellulose microparticles laden hydrogels prepared by spray drying method in comparison with direct loading method.

\section{Cytotoxicity Test}

Cytotoxicity could result from extracts of timolol loaded ethyl cellulose microparticles, or other factors. Cytotoxicity was assessed by incubating cells in media that contained an extracts of microparticles, blank hydrogel, commercial methafilcon contact lens, vehicle (media only, control group). After $24 \mathrm{hrs}$ of exposure, cellular viability was assessed using an MTT colorimetric assay. Compared to cells that were exposed to media only, batch EC-50\%, EC-70\%, EC-85\% and methafilcon contact lens demonstrated cell viabilities of $93.45 \pm 5.42 \%, 96.45 \pm 6.42 \%, 94.45 \pm 4.42 \%$ and $94.65 \pm 2.18 \%$ respectively (Table 5). The viability of cells exposed to extracts of microparticles was not statistically different $(\mathrm{p}>0.05)$ from methafilcon and blank hydrogels. The percentage viability was greater than $70 \%$, thus the microparticles laden hydrogel material was found to be safe for contact lens wear, and can be used for further animal study.

Table 5. Cell viability of statens seruminstitut rabbit corneal cells.

\begin{tabular}{|c|c|}
\hline Hydrogel Type & $\begin{array}{c}\text { \% Cell Viability } \\
\text { (mean } \pm \text { SD, } \mathbf{n}=\mathbf{4})\end{array}$ \\
\hline \hline SLS $(0.01 \mathrm{mg} / \mathrm{ml})$, Positive control & $56.51 \pm 0.42$ \\
\hline Methafilcon lens & $94.65 \pm 2.18$ \\
\hline Blank hydrogel & $95.60 \pm 3.42$ \\
\hline EC-50\% & $93.45 \pm 5.42$ \\
\hline EC-70\% & $96.45 \pm 6.42$ \\
\hline EC-85\% & $94.45 \pm 4.42$ \\
\hline
\end{tabular}




\section{CONCLUSION}

The study demonstrates the limitation of direct loading method to sustain the ophthalmic drug release duration through hydrogel contact lenses. While microparticles laden hydrogels (EC-85\%) showed zero order release kinetics, likely due to ethylcellulose (hydrophobic polymer) which forces the drug molecules to diffuse through long tortuous pathway from microparticles. The hydrogels appeared safe in cytotoxicity study. However, the optical and physical properties of contact lenses were affected due to large particle size in micron range, suggesting the need of nanotechnology and optimization. From this research work, it can be concluded that the concept of loading drug loaded ethyl cellulose microparticles into hydrogels has a strong potential to serve as a good platform for sustained ophthalmic drug delivery.

\section{CONFLICT OF INTEREST}

The authors confirm that this article content has no conflict of interest.

\section{ACKNOWLEDGEMENTS}

This research project was funded by LeoLens Technology, San Diego, California 92128, USA. The authors are grateful to Dr. Akshay R. Koli and Dr. Ketan M. Ranch, Assistant Professors, Maliba Pharmacy College, Gujarat, India for their technical assistance and to Dr. Bhavin A. Vyas, Associate Professor, HOD, Pharmacology Department, Maliba Pharmacy College, for his guidance and cooperation in cytotoxicity study. The author is also thankful to Dr. Renu S. Chauhan, Registrar, Uka Tarsadia University, for her suggestions in language editing.

\section{REFERENCES}

[1] Jung HJ, Chauhan A. Temperature sensitive contact lenses for triggered ophthalmic drug delivery. Biomaterials 2012; 33(7): 2289-300.

[2] Peng C-C, Burke MT, Carbia BE, Plummer C, Chauhan A. Extended drug delivery by contact lenses for glaucoma therapy. J Control Release 2012; 162(1): 152-8.

[3] Le Bourlais C, Acar L, Zia H, Sado PA, Needham T, Leverge R. Ophthalmic drug delivery systems: recent advances. Prog Retinal Eye Res 1998; 17(1): 33-58.

[4] Sahoo SK, Dilnawaz F, Krishnakumar S. Nanotechnology in ocular drug delivery. Drug Discov Today 2008; 13(3): 144-51.

[5] Alexander A, Khan J, Giri TK, Tripathi DK, Saraf S, Saraf S. Advancement in stimuli triggered in situ gelling delivery for local and systemic route. Exp Opin Drug Deliv 2012; 9(12): 1573-92.

[6] Srividya B, Cardoza RM, Amin P. Sustained ophthalmic delivery of ofloxacin from a $\mathrm{pH}$ triggered in situ gelling system. J Control Release 2001; 73(2): 205-11.

[7] Maudgal PC, De Clercq K, Descamps J, Missotten L. Topical treatment of experimental herpes simplex keratouveitis with 2'-Oglycylacyclovir: A water-soluble ester of acyclovir. Arch Ophthalmol 1984; 102(1): 140-2.

[8] Ruel-Gariépy E, Leroux J-C. In situ-forming hydrogels: review of temperature-sensitive systems. Eur J Pharm Biopharm 2004; 58(2): 409-26.

[9] Nanjawade BK, Manvi F, Manjappa A. In situ-forming hydrogels for sustained ophthalmic drug delivery. J Control Release 2007; 122(2): 119-34.

[10] Aggarwal D, Pal D, Mitra AK, Kaur IP. Study of the extent of ocular absorption of acetazolamide from a developed niosomal formulation, by microdialysis sampling of aqueous humor. Int $\mathbf{J}$ Pharm 2007; 338(1): 21-6.
[11] Haznedar S, Dortunc B. Preparation and in vitro evaluation of Eudragit microspheres containing acetazolamide. Int J Pharm 2004; 269(1): 131-40.

[12] Bourges J, Bloquel C, Thomas A, et al. Intraocular implants for extended drug delivery: therapeutic applications. Adv Drug Deliv Rev 2006; 58(11): 1182-202.

[13] Gupta H, Aqil M, Khar R, et al. Development and characterization of $99 \mathrm{mTc}$-timolol maleate for evaluating efficacy of in situ ocular drug delivery system. AAPS PharmSci Tech 2009; 10(2): 540-6.

[14] Nichols J. Overview of general contact lens market trends. Contact Lens Spectrum 2014; 29(1): 22-8.

[15] Kerr C, Ruston D. The ACLM Contact Lens Year Book 2012. Devizes, Wiltshire, UK: The Association of Contact Lens Manufacturers 2012

[16] Morgan PB, Efron N. A decade of contact lens prescribing trends in the United Kingdom (1996-2005). Cont Lens Anter Eye 2006; 29(2): 59-68.

[17] McNamara NA, Polse KA, Brand RJ, Graham AD, Chan JS, McKenney $\mathrm{CD}$. Tear mixing under a soft contact lens: effects of lens diameter. Am J Ophthalmol 1999; 127(6): 659-65.

[18] Creech J, Chauhan A, Radke C. Dispersive mixing in the posterior tear film under a soft contact lens. Indus Eng Chem Res 2001; 40(14): 3015-26.

[19] Zhu H, Chauhan A. Effect of viscosity on tear drainage and ocular residence time. Optometry Vision Sci 2008; 85(8): E715-E25.

[20] Li C-C, Chauhan A. Modeling ophthalmic drug delivery by soaked contact lenses. Indus Eng Chem Res 2006; 45(10): 3718-34.

[21] Alvarez-Lorenzo C, Hiratani H, Concheiro A. Contact lenses for drug delivery. Am J Drug Deliv 2006; 4(3): 131-51.

[22] Sedlavek J. Possibilities of application of ophthalmic drugs with the aid of gel contact lens. Cesk Oftalmol 1965; 21(1): 509-14.

[23] Li C-C, Abrahamson M, Kapoor Y, Chauhan A. Timolol transport from microemulsions trapped in HEMA gels. J Coll Interf Sci 2007; 315(1): 297-306.

[24] Gulsen D, Li C-C, Chauhan A. Dispersion of DMPC liposomes in contact lenses for ophthalmic drug delivery. Cur Eye Res 2005; 30(12): 1071-80

[25] Kim J, Peng C-C, Chauhan A. Extended release of dexamethasone from silicone-hydrogel contact lenses containing vitamin E. J Control Release 2010; 148(1): 110-6.

[26] Kapoor Y, Chauhan A. Ophthalmic delivery of Cyclosporine A from Brij-97 microemulsion and surfactant-laden p-HEMA hydrogels. Int J Pharm 2008; 361(1): 222-9.

[27] Hiratani H, Alvarez-Lorenzo C. Timolol uptake and release by imprinted soft contact lenses made of N,N-diethylacrylamide and methacrylic acid. J Control Release 2002; 83(2): 223-30.

[28] Peng C-C, Chauhan A. Extended cyclosporine delivery by silicone: hydrogel contact lenses. J Control Release 2011; 154(3): 267-74.

[29] Gulsen D, Chauhan A. Dispersion of microemulsion drops in HEMA hydrogel: a potential ophthalmic drug delivery vehicle. Int J Pharm 2005; 292(1): 95-117.

[30] Guzman-Aranguez A, Colligris B, Pintor J. Contact lenses: promising devices for ocular drug delivery. J Ocular Pharmacol Therap 2013; 29(2):189-99.

[31] Munier A, Gunning T, Kenny D, O'Keefe M. Causes of blindness in the adult population of the Republic of Ireland. Br J Ophthalmol 1998; 82(6): 630-3.

[32] Blomdahl S, Calissendorff B, Tengroth B, Wallin Ö. Blindness in glaucoma patients. Acta Ophthalmol Scand 1997; 75(5): 589-91.

[33] Lavik E, Kuehn M, Kwon Y. Novel drug delivery systems for glaucoma. Eye 2011; 25(5): 578-86.

[34] Fraunfelder F, Meyer SM. Systemic side effects from ophthalmic timolol and their prevention. J Ocular Pharmacol Therap 1987; 3(2): $177-84$

[35] Plummer CE, MacKay EO, Gelatt KN. Comparison of the effects of topical administration of a fixed combination of dorzolamidetimolol to monotherapy with timolol or dorzolamide on IOP, pupil size, and heart rate in glaucomatous dogs. Vet Ophthalmol 2006; 9(4): 245-9.

[36] Wilkie D, Latimer C. Effects of topical administration of timolol maleate on intraocular pressure and pupil size in dogs. Am J Vet Res 1991; 52(3): 432-5.

[37] Freitas C, Müller RH. Spray-drying of solid lipid nanoparticles. Eur J Pharm Biopharm 1998; 46(2): 145-51.

[38] Fu Y-J, Shyu S-S, Su F-H, Yu P-C. Development of biodegradable co-poly (D, L-lactic/glycolic acid) microspheres for the controlled 
release of 5-FU by the spray drying method. Colloids Surface B 2002; 25(4): 269-79.

[39] Jung HJ, Abou-Jaoude M, Carbia BE, Plummer C, Chauhan A. Glaucoma therapy by extended release of timolol from nanoparticle loaded silicone-hydrogel contact lenses. J Control Release 2013; 165(1): 82-9.

[40] Maulvi FA, Dalwadi SJ, Thakkar VT, Soni TG, Gohel MC, Gandhi TR. Improvement of dissolution rate of aceclofenac by solid dispersion technique. Powder Technol 2011; 207(1): 47-54.

[41] Hammond C. The basics of crystallography and diffraction. Oxford: University Press Oxford 2009.

[42] Dantuluri AK, Amin A, Puri V, Bansal AK. Role of $\alpha$-relaxation on crystallization of amorphous celecoxib above $\mathrm{T} g$ probed by dielectric spectroscopy. Mol Pharm 2011; 8(3): 814-22.

[43] Qian F, Tao J, Desikan S, Hussain M, Smith RL. Mechanistic investigation of Pluronic ${ }^{\circledR}$ based nano-crystalline drug-polymer solid dispersions. Pharm Res 2007; 24(8): 1551-60.

[44] Alvarez-Lorenzo C, Yañez F, Barreiro-Iglesias R, Concheiro A. Imprinted soft contact lenses as norfloxacin delivery systems. J Control Release 2006; 113(3): 236-44.

[45] Hamdan II, Qurani H. Development and validation of a HPLC method for determination of potential residual cortisone compounds in timolol maleate eye drops. J Liq Chromatogr Relat Technol 2008; 32(3): 449-67.

[46] Agarwal A, Tiwari S, Nagariya K. Method development and its validation for quantitative simultaneous determination of Latanoprost, Timolol and Benzalkonium chloride in ophthalmic solution by RP-HPLC. J Drug Deliv Therap 2013; 3(2): 26-30.

[47] White CJ, McBride MK, Pate KM, Tieppo A, Byrne ME. Extended release of high molecular weight hydroxypropyl methylcellulose from molecularly imprinted, extended wear silicone hydrogel contact lenses. Biomaterials 2011; 32(24): 5698-705.

[48] Pozuelo J, Compañ V, González-Méijome JM, González M, Mollá S. Oxygen and ionic transport in hydrogel and silicone-hydrogel contact lens materials: An experimental and theoretical study. J Membr Sci 2014; 452: 62-72.

[49] Yañez F, Martikainen L, Braga ME, et al. Supercritical fluidassisted preparation of imprinted contact lenses for drug delivery. Acta Biomat 2011; 7(3): 1019-30.

[50] Costa VP, Braga ME, Duarte CM, et al. Anti-glaucoma drugloaded contact lenses prepared using supercritical solvent impregnation. J Supercrit Fluids 2010; 53(1): 165-73.

[51] Dash S, Murthy PN, Nath L, Chowdhury P. Kinetic modeling on drug release from controlled drug delivery systems. Acta Pol Pharm 2010; 67(3): 217-23.

[52] Maulvi FA, Soni TG, Shah DO. Effect of timolol maleate concentration on uptake and release from hydrogel contact lenses using soaking method. J Pharm Appl Sci 2014; 1(1): 17.

[53] Ali M, Horikawa S, Venkatesh S, Saha J, Hong JW, Byrne ME. Zero-order therapeutic release from imprinted hydrogel contact lenses within in vitro physiological ocular tear flow. J Control Release 2007; 124(3): 154-62.

[54] Mencucci R, Pellegrini-Giampietro DE, Paladini I, Favuzza E, Menchini U, Scartabelli T. Azithromycin: assessment of intrinsic cytotoxic effects on corneal epithelial cell cultures. Clin Ophthalmol (Auckland, NZ) 2013; 7: 965-71.

[55] Hsiao M-H, Chiou S-H, Larsson M, et al. A temperature-induced and shear-reversible assembly of latanoprost-loaded amphiphilic chitosan colloids: Characterization and in vivo glaucoma treatment. Acta Biomater 2014; 10(7): 3188-96.

[56] Markku P. S-timolol hemihydrate composition and method of preparation therefor. United States patent US 5574035 A. 1996 Nov.

[57] Chen X, Ji ZL, Chen YZ. TTD: therapeutic target database. Nucleic Acids Res 2002; 30(1): 412-5.

[58] A Maulvi F, T Thakkar V, G Soni T, R Gandhi T. Optimization of aceclofenac solid dispersion using box-behnken design: in-vitro and in-vivo evaluation. Cur Drug Deliv 2014; 11(3): 380-91.

Received: November 30, 2014

Revised: February 18, 2015

Accepted: March 09, 2015

(C) Maulvi et al.; Licensee Bentham Open.

This is an open access article licensed under the terms of the Creative Commons Attribution Non-Commercial License (http://creativecommons.org/licenses/by-nc/3.0/) which permits unrestricted, non-commercial use, distribution and reproduction in any medium, provided the work is properly cited. 